\title{
AVALIAÇÃO DOS PRINCIPAIS FATORES QUE IMPACTAM À GESTÃO E CONTROLE DE ESTOQUE DO SEGMENTO DE PRODUTOS MÉDICOS
}

\author{
EVALUATION OF THE MAIN FACTORS THAT IMPACT ON THE STOCK \\ MANAGEMENT AND CONTROL OF THE MEDICAL PRODUCTS SEGMENT
}

\author{
Recebimento: 12/05/2018 - Aceite: 21/12/2018 - Publicação: 31/01/2019 \\ Processo de Avaliação: Double Blind Review
}

Luiz Claudio Gonçalves

Doutor em Engenharia de Produção

Faculdade de Tecnologia da Zona Sul de SP

luizgoncalves@uol.com.br

Geisa Alves do Nascimento

Tecnóloga em Logística

Faculdade de Tecnologia da Zona Sul de SP

geisa.alves@gmail.com

Gabriela Silva Dias

Tecnóloga em Logística

Faculdade de Tecnologia da Zona Sul de SP

gabriella.dsilva@hotmail.com

Guilherme Sampaio Paixão

Tecnólogo em Logística

Faculdade de Tecnologia da Zona Sul de SP

guilhermespaixao@hotmail.com

\section{RESUMO}

O equilíbrio entre o estoque e o nível de serviço visando atender as necessidades do cliente, não é tarefa fácil e exige um árduo planejamento. Além disso, há fatores processuais e operacionais que impactam diretamente na gestão e controle de estoques acarretando altos custos e retrabalhos. $\mathrm{O}$ presente artigo apresenta esses fatores, por meio de um estudo de caso em uma empresa do ramo da saúde. Aborda os processos relacionados à gestão e controle de estoque da empresa, analisando os aspectos operacionais que podem comprometer o nível de serviço. O mesmo busca, também, evidenciar as perdas e os custos decorrentes dos processos de estoque, propondo sugestões de melhorias. Os resultados obtidos na pesquisa apontam que a empresa investigada desempenha processos, que podem ser otimizados por meio da efetiva aplicação do método de avaliação de estoque FEFO, visto que, a quantidade de material fora da validade é significativa. $\mathrm{O}$ incorreto descarte desses materiais, além das perdas com produtos avariados e não conformes geram custos, os quais poderiam ser parte da receita. Não obstante, também foi observado que, a falta do devido acompanhamento por parte dos gestores impacta no desempenho e comportamento dos colaboradores, no que se refere aos procedimentos executados, visto que, as análises realizadas na pesquisa evidenciam que 
muitos dos equívocos observados são decorrentes da falta de atenção, por parte dos colaboradores.

Palavras-chaves: gestão de estoque, controle de estoque, métodos de avaliação de estoque

\section{ABSTRACT}

The management and stock control are essential for the financial health of the company and also to keep it competitive in the market. Balancing stock and the level of service to meet the customer is no easy task and requires a lot of planning. However, there are procedural and operational aspects that impact on the management and stock control, causing costs and rework. The present article presents these factors through a case study in a health care company that has been in the market for more than a century and a half. The work, addresses the processes related to the management and stock control of the company and analyzes the operational aspects that can compromise the quality of service level and customer service. In addition, the same seeks to evidence the losses and costs arising from the stock processes of the investigated organization, proposing suggestions for improvements. However, it was observed in the present research that the investigated company performs processes that can be optimized by means of the FEFO stock valuation method, since the amount of expired material is significant. Disposal of these materials, in addition to losses with broken and noncompliant products, generate costs that could be part of the revenue or billing. However, it was also observed that management follow-up has an impact on the performance and behavior of employees, regarding the procedures performed, given that the analysis described in the article shows that some misconceptions are due to lack of attention on the part of employees.

Keywords: stock management, inventory control, valuation methods

\section{INTRODUÇÃO}

Conforme Martins e Campos Alt (2009) existem várias técnicas de gestão e controle de estoques, que impactam diretamente nas estratégias de sucesso das empresas. Com base nessa argumentação, o presente artigo focou investigar o seguinte problema de pesquisa: Quais são os principais fatores que podem impactar no processo de gestão e controle de estoque de uma empresa de produtos médicos?

Com base na investigação desse problema de pesquisa, o artigo teve como principal objetivo apresentar algumas técnicas e ferramentas de gestão e controle de estoque, bem como identificar e avaliar quais foram os impactos gerados pela utilização dessas técnicas e ferramentas na competitividade e nos custos operacionais de uma empresa do setor de fabricação de produtos médicos situada no interior do estado de São Paulo. Para tal, foi realizada uma pesquisa qualitativa, descritiva, estudo de caso, a qual foi aplicado à empresa

Revista ENIAC Pesquisa, Guarulhos (SP), V.8, n.1, jan.- jun. 2019. 
XYZ Comércio de Produtos Médicos Ltda, empresa essa que está no mercado há mais de 160 anos, fabricando, importando e distribuindo materiais cirúrgicos ortopédicos. Cabe salientar que, a realização dessa investigação permitiu a sugestões de algumas melhorias processuais e minimização de perdas à empresa investigada.

Para Martelli e Dandaro (2015) todas as organizações, independente do segmento, devem contemplar a gestão e controle de estoques como peculiaridades de grande importância para a saúde financeira e competitividade das mesmas no mercado. No entanto, se os processos operacionais e de gestão, não forem empregados e aplicados da maneira correta, a empresa, fatalmente terá problemas com seu estoque e com seu faturamento, além de correr o risco de apresentar um nível de serviço inadequado. Desse modo, a realização dessa investigação se faz necessário visando-se avaliar os aspectos que afetam de forma a gestão e o controle de estoque, para que se possa identificar o efetivo impacto gerado em termos de custos para as empresas e, assim sugerir melhorias que busquem minimizar alguns possíveis equívocos gerenciais.

\section{REFERENCIAL TEÓRICO}

\subsection{ESTOQUE}

Segundo Gonçalves (2017), o estoque é quaisquer quantidades de materiais e/ou bens que ficam alocados na organização, em que estão temporariamente improdutivos, porém, com previsão de serem usados no futuro. Em outras palavras, pode-se dizer que seria o conjunto de itens tangíveis que a empresa tem alocado, tendo como objetivo suprir as necessidades da demanda.

De acordo com Dantas (2015) todo material que se encontra armazenado em quantidade expressiva para ser aproveitado ou comercializado é denominado de estoque. Quando se trata de estoque para comércio, os bens são guardados para futuras vendas. Na indústria o estoque é de itens usados para a fabricação do produto. Já na prestação de serviço, são os itens (bens) alocados para serem utilizados no desenvolvimento da operação da empresa.

A gestão de estoque, na visão de Gomes e Milan (2017) e Ribeiro et al. (2017) é o processo responsável por propiciar a quantidade certa de insumos para fabricação, bem como conceder produtos para serem comercializados, de maneira que, o produto não falte e não

Revista ENIAC Pesquisa, Guarulhos (SP), V.8, n.1, jan.- jun. 2019. 
proporcione atrasos operacionais. O gestor dessa área tem a incumbência de garantir o funcionamento contínuo e ininterrupto da operação da empresa.

Observa Costa (2015) que a gestão de estoques é um conjunto de atividades que visa, por meio das respectivas políticas de estoques, a máxima eficiência e o menor custo, na busca da otimização e equilíbrio entre o estoque (produção) e consumo (demanda), de tal forma que para Gonçalves (2017), as reais necessidades dos clientes sejam atendidas e agradadas, com o menor custo de estoque possível e que seja garantida aos clientes a continuidade do fornecimento, para que se alcance o maior nível de serviço imaginável.

A gestão de estoques tem duas funções: planejamento e controle. A primeira permite estratégias que visam alcançar os objetivos definidos para a empresa como um todo. A segunda busca otimização do nível de serviço reduzindo custos e estoques desnecessários. (DORNIER et al, 2007)

Já para Hugo et al. (2015) a gestão de estoque visa equilibrar a disponibilidade de produtos e os custos relacionados com a manutenção de estoques.

Em se tratando de controle de estoque, cabe destacar que esse processo vai muito além do que apenas acondicionar os itens organizados no seu devido lugar. Segundo Andrade (2011), controle de estoque é o procedimento aplicado para registrar, fiscalizar e gerir a entrada e saída de mercadorias e produtos seja em indústria ou no comércio. Esse procedimento é indispensável quando o assunto é estoque, a empresa que não realiza o planejamento da produção segundo a demanda, se arrisca, pois pode deter matéria prima remanescente ou ausência da mesma.

De acordo com Martelli e Dandaro (2015), pode-se definir controle de estoque como uma sequência de informações que possibilita confrontar o resultado real da performance programada.

Dentz (2016) salienta que esse processo de controle do estoque pode ser classificado em 4 fases:

Fase 1.: $\quad$ No início, quando é necessário atentar para o espaço onde os itens vão ficar alocados, devendo ser um local estruturado e limpo. É preciso que esteja estabelecida conforme as exigências de armazenamento (ambiente, umidade, fluxo de ar, entre outros).

Revista ENIAC Pesquisa, Guarulhos (SP), V.8, n.1, jan.- jun. 2019. 
Fase 2.: $\quad$ Deve se refletir, pois o controle de estoques inclui vários processos e etapas, para ser realizado com maior efetividade são dividas e delegadas para os responsáveis.

Fase 3.: $\quad$ Uma das partes mais criteriosas do processo de controle é estar bem alinhado as entradas e saídas, quanto mais claras e assertivas estiverem as informações mais simples são as formas de resolução.

Fase 4.: $\quad$ Deter fornecedores de alta confiabilidade e programar períodos para compra, é preciso para diminuir falhas que ocorrem por falta de itens armazenados, além de possibilitar prazos de pagamento, quando for preciso.

Outro ponto para citar é a busca pelo equilíbrio, com auxílio dos fornecedores e parceiros, para não deixar de vender nem manter mercadorias paradas em estoque.

\subsection{TÉCNICAS E FERRAMENTAS APLICADAS AO CONTROLE DE ESTOQUE}

A) O Inventário Físico é uma ferramenta muito relevante para o controle de estoques, haja vista que consiste na contagem física de todos os itens de estoque levando em consideração o período de referência. Para Vicenzi e Silva (2014), o inventário envolve a verificação dos saldos físicos existentes no estoque com a precisão das informações contidas nos registros dos sistemas, sendo de suma importância para se ter uma exatidão com relação a movimentação de estoque. Na visão de Almeida, Saraiva e Souza $(2015$, p.9) “o inventário é o primeiro passo para o planejamento inicial de uma boa gestão de estoque, sendo imprescindível para prever as dificuldades e com isso elaborar ações preventivas”.

Conforme Mondardo Junior (2016), de acordo com a frequência que o inventário é feito, esse é classificado de duas formas:

- Periódico: São contagens realizadas em determinados períodos, de acordo com a política de controle de estoque seguida pela empresa, normalmente ocorrendo apenas em períodos trimestrais, semestrais, anual ou no encerramento do ano fiscal.

- Rotativo: A contagem é realizada permanentemente no decorrer do período fiscal, de modo que todos os itens sejam contados, pelo menos uma vez, o que torna importante para identificar de maneira rápida os erros no controle de estoque.

B) A Análise da Curva ABC - ou 80/20 - teve seu princípio baseado no conceito de Vilfredo Pareto. Do ponto de vista de Vieira (2016), Pareto constatou que uma pequena 
parcela da população local, obtinha a maior parte da riqueza, ou seja, $20 \%$ da população concentrava $80 \%$ da renda absoluta da localidade. Esse estudo, anos depois foi propagado para outras atividades e foi essencialmente importante para os profissionais que controlam o estoque.

Conforme Serafim (2016), a análise da curva ABC trata-se de um método de controle de estoque, que classifica os itens de estoque segundo seu grau de importância, para que haja uma classificação de itens de estoques $(\mathrm{A}, \mathrm{B}, \mathrm{C})$ em função da relação quantidade de itens em estoque versus o seu impacto econômico. Nesse sentido essa análise avalia qual é o impacto econômico que essa quantidade de itens ocasiona no valor monetário total do estoque existente.

De acordo com Petroli e Júnior (2012), a análise da curva ABC é utilizada visando-se estabelecer prioridades para programação da produção, além de servir como um parâmetro o qual informa a necessidade de aquisição de mercadorias ou matérias-primas essenciais para o controle de estoque.

Segundo Pozo (2007), a técnica denomina-se Curva ABC, em razão de se classificar os dados obtidos em três categorias distintas, que são:

1) Itens da Classe A: São os itens de maior importância, apesar de ter poucas quantidades, e que devem receber toda a atenção no primeiro momento do estudo, por terem grande impacto financeiro.

2) Itens da Classe B: São os itens intermediários e que deverão ser analisados logo após as definições sobre os itens da classe A.

3) Itens da Classe C: São os itens menos importantes, embora possuam grandes quantidades, porém com valor monetário reduzido, sendo possível um maior espaço de tempo para sua análise e tomada de ação.

Cabe ressaltar que, na visão de Gonçalves (2017) não há uma regra específica para que a classificação do porcentual dos itens que pertencem a classe A, B ou C, seja sempre da mesma forma. Fica a cargo de cada empresa analisar sua realidade e elaborar a classificação, de acordo com a importância que cada item representa para si, conforme o quadro 2:

Quadro 02 - Classificação dos itens ABC.

Revista ENIAC Pesquisa, Guarulhos (SP), V.8, n.1, jan.- jun. 2019. 


\begin{tabular}{|c|c|c|}
\hline CLASSES & QUANTIDADE (\%) & $\begin{array}{c}\text { IMPACTO FINANCEIRO } \\
(\%)\end{array}$ \\
\hline $\mathrm{A}$ & $10 \mathrm{a} 20$ & $60 \mathrm{a} 70$ \\
\hline $\mathrm{B}$ & $20 \mathrm{a} 30$ & $20 \mathrm{a} 30$ \\
\hline $\mathrm{C}$ & $50 \mathrm{a} 60$ & $5 \mathrm{a} 10$ \\
\hline
\end{tabular}

Fonte: Gonçalves (2017)

Dessa forma, uma quantidade mínima de mercadorias em estoque pode gerar mais lucro em relação à maioria dos itens disponíveis. Com esse método de controle de estoque, conforme Pontes (2013) é possível identificar quais itens justificam atenção e tratamento adequado quanto a sua gestão, os que causam impactos consideráveis no faturamento da empresa e quais são imprescindíveis em se ter em estoque.

C) Acuracidade - para um efetivo controle de estoque, a medição da acuracidade é um aspecto bastante relevante. Para Silva e Cardoso (2016), a acuracidade pode ser medida pela contagem física em estoque, em comparação com a quantidade registrada em sistema, para identificar o percentual entre os itens registrados em sistema e dos itens conferidos fisicamente no estoque.

De acordo com Maciel (2017, p.29), "O termo acurácia é originário da palavra inglesa "accuracy" e significa a qualidade daquilo que é correto, previsto e exato."

Maciel (2017) salienta ainda que, o resultado ideal para se alcançar é 100\%, mas é muito difícil de atingir essa porcentagem na prática. Cabe a cada empresa determinar qual é o porcentual de acurácia aceitável que essa deve obter. É importante para as empresas adotarem graus de erros toleráveis entre as quantidades no físico e no sistema, porém na visão de Monfron (2013), os principais motivos que podem afetar a performance do estoque e diminuir a acuracidade são:

- Realização incorreta das entradas e saídas dos itens em estoque;

- Deixar de atualizar os sistemas de controle de estoque ou atualiza-los duplamente;

- $\quad$ Procedimentos de armazenagem mal elaborados, de modo que possa efetuar transferências (entradas e saídas) sem documentação ou autorização apropriada;

- Utilização de sistemas ineficientes de controle de estoques;

Revista ENIAC Pesquisa, Guarulhos (SP), V.8, n.1, jan.- jun. 2019. 
- $\quad$ Sequência de armazenagem que não mantém uma proximidade entre itens similares, em que facilitaria a identificação;

- $\quad$ Sistemas de codificação mal elaborados, confusos e extensos.

Tendo em vista esses dados, os quais afetam o desempenho do estoque, é imprescindível salientar, segundo Rodrigues, Guimarães e Severo (2013), que os estoques de uma organização, por representarem importante parte do investimento de capital, requerem um controle constante, focado em diminuir as divergências frequentemente encontradas.

D) Giro de Estoque - conforme Borges (2014) no Brasil, a gestão e o controle de estoque é uma causa de grande dimensão para as empresas, pois viabiliza maior controle de seus recursos, dando a instituição um diferencial. Atualmente é investido um alto capital em estoques e tende a aumentar constantemente. Considerando sua enorme importância, todas as ferramentas que auxiliam a um bom resultado do controle de estoque são indispensáveis.

O giro de estoque é "o número de vezes em que o estoque de determinado item é renovado em um período de tempo (FRANCISCHINI E GURGEL, 2002, p. 161)”.

\title{
2.3. MÉTODOS DE AVALIAÇÃO DE ESTOQUE
}

Dentre os métodos de avaliação de estoque, o custo médio é utilizado com mais frequência nas empresas.

Para Francischini e Gurgel $(2002,171)$ :

\begin{abstract}
A fórmula existente para chegar ao resultado do valor médio, utiliza valor total em estoque do item / número de itens em estoque. Neste enquadramento, utilizando a média entre o montante do custo total dos estoques e o montante das quantidades, resultando em um valor médio das unidades.
\end{abstract}

Segundo Martins (2003) o custo médio tem um resultado estabilizante, pois nivela as alterações de preços, trazendo também a um período maior os reais custos de aquisição de materiais. A título de exemplo, determinado item custou para a companhia em um primeiro momento R\$ 10,00, em um segundo período $\mathrm{R} \$ 15,00$ e em um terceiro $\mathrm{R} \$ 20,00$. Considerando a média dos valores diferentes em cada período, o custo médio desse item terá um valor de $\mathrm{R} \$ 15,00$.

Revista ENIAC Pesquisa, Guarulhos (SP), V.8, n.1, jan.- jun. 2019. 
Rosa (2014) destaca que, a explicação para a grande parte das companhias brasileiras optarem por esse método é devido ao ato de que esse oferece um valor menor na provisão do imposto de renda quando confrontado aos outros métodos

Além do custo médio, pode-se também destacar outros métodos que também são utilizados na avaliação de estoques, tais como:

- $\quad$ FIFO (First In, First Out) ou PEPS (Primeiro que entra, Primeiro que sai) esse método de controle de estoque segue uma ordem lógica, o primeiro item que entra para ser armazenado é o primeiro que sai. O controle é feito pela data de entrada do lote, remetendo ao sistema de dados do tipo fila. Esse método é muito utilizado, pois realiza um fluxo natural, indicado para indústrias alimentícias e eletrônicas. Nesse sentido, Jacobsen (2011, p. 76) ressaltam que, “o controle é feito pela ordem cronológica das entradas. Sai o material que primeiro integrou o estoque, sendo substituído pela mesma ordem cronológica em que foi recebido".

FEFO (First-Expire, First-Out) - método utilizado em empresas que estocam produtos com data de vencimento curta, essa técnica busca classificar a saída dos itens pelo seu vencimento. A ferramenta é um avanço do FIFO, porém não muito comum. Esse processo é aplicado nos setores alimentício, farmacêutico e hospitalares, onde é possível conter o desaproveitamento dos materiais vencidos colocando-os para fora do estoque antes da expiração da data de vencimento. Conforme Duarte (2015) é voltado para um estoque de alto giro, itens com shelflife, ou seja, vida útil ou prazo de validade.

- $\quad$ LIFO (Last-in, First-out) ou UEPS (Último a entrar, primeiro a sair) - técnica que consiste em tirar primeiro do estoque o último item que entra, seguindo esse fundamento, Almeida (2010, p.196) menciona que:

- Nesse método, as quantidades ficam em estoque são valorizadas pelos primeiros custos unitários e as que saem são valorizadas pelos últimos custos unitários. Esse método não é aceito pelo pronunciamento técnico CPC 16.

Dessa forma, o LIFO não é indicado para estoques que apresentam um giro muito longo, pois existe o risco dos itens estocados danificarem ou passar o prazo de validade, evitando as perdas para a empresa, em geral é utilizado em produtos que não vencem e tem uma durabilidade maior.

\section{METODOLOGIA}

Revista ENIAC Pesquisa, Guarulhos (SP), V.8, n.1, jan.- jun. 2019. 
A investigação foi embasada em uma pesquisa qualitativa, descritiva e bibliográfica, apoiada em um estudo de caso realizado em fevereiro de 2018, em uma empresa do segmento de produtos médicos, situada no município de Diadema (SP).

Cabe destacar que os dados coletados para a análise do estudo de caso são provenientes de visitas técnicas às instalações da empresa pesquisada, bem como da experiência profissional de um dos autores da pesquisa, o qual é funcionário da mesma. Além disso, os dados também puderam ser obtidos, por meio da participação de alguns gestores da empresa, os senhores Alex Araújo (analista de logística) e o senhor Claudio Diogo (analista de qualidade), os quais responderam um questionário via e-mail nos dias 01 e 06/11 de 2017 . Houve também a participação do senhor Cirilo Lira (encarregado de logística), que respondeu o mesmo questionário no dia 26/11 de 2017. Por fim a coleta de dados foi complementada com a avaliação de diversos relatórios operacionais fornecidos pela empresa.

\section{RESULTADOS E DISCUSSÕES}

\subsection{HISTÓRICO DA EMPRESA}

A empresa "XYZ Comércio de Produtos Médicos Ltda" é de origem inglesa e atua no ramo de produtos médicos. Segundo o site da empresa investigada, a mesma foi fundada em 1856 na cidade de Hull, Inglaterra. A mesma era uma pequena farmácia que pertencia a um químico dispensador que fabricava curativos cirúrgicos. Sua expansão se deve a ocorrência da $1^{\text {a }}$ Guerra Mundial, em 1914, a qual forneceu curativos para a Grã-Bretanha, França, Bélgica, Sérvia, para o exército e Cruz Vermelha americanos. Atualmente, a empresa fabrica e vende equipamentos multifuncionais, produtos altamente avançados para tratamento de feridas difíceis de curar (curativos), produtos para $\operatorname{artroscopia}^{2}$ (medicina esportiva), produtos para trauma e produtos ortopédicos de reconstrução ${ }^{3}$ para joelho, ombro e quadril.

\footnotetext{
${ }^{1} \mathrm{~A}$ empresa investigada recebe o nome fictício "XYZ Comércio de Produtos Médicos Ltda", pois solicitou sigilo de sua identificação.

${ }^{2}$ Artroscopia, ou vídeo artroscopia, é o nome que se dá a uma técnica cirúrgica minimamente invasiva ortopédica. Consiste em se abordar uma articulação através de pequenas incisões e instrumentos cirúrgicos especiais. (KARPSTEIN, 2017).

${ }^{3}$ Reconstrução ortopédica: sistemas de substituição articular para joelhos, ombros e quadris (www.smith-nephew.com).
}

Revista ENIAC Pesquisa, Guarulhos (SP), V.8, n.1, jan.- jun. 2019. 
Com sede em Londres, atua em mais de 100 países, sendo que no Brasil seu centro de distribuição fica no município de Diadema (SP) e atende hospitais e pequenas distribuidoras. Emprega em torno de 15 mil funcionários no mundo.

O portfolio de produtos da empresa é dividido em duas linhas:

a) Os ASD`s (Advanced Surgical Devices - Dispositivos Cirúrgicos Avançados) são os instrumentais, descartáveis, implantes, próteses, parafusos e lâminas.

b) Os AWM`s (Advanced Wound Management - Tratamento Avançado de Feridas): são os curativos, os quais são aplicados à vários tipos e grau de ferimentos.

\subsection{ANÁLISE DOS DADOS COLETADOS NA EMPRESA}

\section{A) Análise do perfil do estoque da empresa}

De acordo com os dados obtidos, a empresa dispõe de um estoque com aproximadamente 3200 SKU's e 51 mil lotes. Esse estoque é subdividido em:

- Estoque de produto acabado: destinado aos materiais que já passaram pelo processo de nacionalização e que partir daí ficam disponíveis para venda.

- Estoque pulmão: conhecido tecnicamente por "buffer" busca amortecer os impactos que a empresa recebe de necessidades do mercado. É mantido para ocorrência de atrasos ou qualquer urgência eventual.

- Estoque de segurança: serve para manter o ressuprimento do estoque (itens faltantes) em casos de variabilidade da demanda, problemas com entrega etc.

Para controlar o estoque a empresa utiliza as ferramentas, Curva $\mathrm{ABC}$, inventário cíclico e o método FEFO de avaliação de estoque.

\section{B) Análise do processo de gestão e controle de estoque existente na empresa.}

A análise dos dados obtidos na investigação permitiu o entendimento do processo de gestão e controle de estoque realizado pela empresa, o qual é composto pelos seguintes subprocessos:

1) Recebimento e endereçamento: o recebimento é o processo cuja finalidade é recepcionar os produtos e aceitá-los (ou não) de acordo com as especificações da nota físcal ou número de documento. Após o lançamento da nota fiscal no ERP (Protheus da empresa

Revista ENIAC Pesquisa, Guarulhos (SP), V.8, n.1, jan.- jun. 2019. 
TOTVS), o material é reconferido e endereçado no estoque de produto semiacabado. Cabe também destacar que, em casos de divergências, seja por quantidade ou avarias, o responsável pela conferência executa o registro no Relatório de Não Conformidade (RNC) e transfere o saldo sistêmico e físico para o armazém da Quarentena, que é gerido e controlado pela equipe da Qualidade.

2) Nacionalização: todo produto que chega à empresa é importado, devido a esses serem fabricados fora do Brasil (Inglaterra e Estados unidos). Dessa forma, há a necessidade da nacionalização dos itens, para que os profissionais de saúde dos hospitais tenham o devido conhecimento das informações dos produtos. Nesse processo, os materiais são devidamente etiquetados com identificação em português, tais como, registro da ANVISA, tipo de esterilização, lote, data de vencimento e data de impressão do rótulo. No entanto, esse processo só é feito, após a autorização da equipe de Qualidade. A rotulagem é feita manualmente e funciona como uma linha de produção.

3) Armazenagem: com a finalização do processo de nacionalização, os materiais passam a ser considerados produtos acabados. Portanto, são liberados para venda e armazenados ou endereçados nas posições que já constam saldo físico e sistêmico dos itens recentemente recebidos.

4) Separação manual: assim que é feita uma requisição do cliente, o material é separado manualmente via coletor de dados (WMS - Warehouse Management System). Entretanto, a separação de ASD é realizada por colaboradores responsáveis pelo pedido de venda dessa linha de produto. Já a separação manual de AWM é feita pelos funcionários da expedição.

5) Expedição: na empresa $X Y Z$, os funcionários da expedição, não só fazem as atividades acima descritas, mas também separam pedidos de AWM. A separação é feita via coletor (WMS). Além disso, também conferem o material e faturam a nota fiscal para expedir o pedido do cliente.

\section{C) Análise dos possíveis equívocos operacionais existentes na empresa}

1) Organização do estoque: a organização do estoque (físico) é o primeiro ponto de atenção e melhoria no aspecto operacional. Nota-se que, nem todos os materiais se encontram organizados em seus endereços, sendo que, várias prateleiras apresentam desordem e SKU's misturados. Verifica-se também que, não há um senso de organização de alguns 
colaboradores, pois, percebe-se que, se um funcionário está preocupado em fazer a alocação do item de forma organizada, outro acondiciona de forma inadequada, ou desordena aqueles itens que já formam organizados. Essa constatação é decorrente de observações feitas na movimentação do estoque durante o período de coleta de dados.

2) Endereçamento dos materiais: em relação aos endereçamentos percebe-se que há vários produtos do mesmo tipo espalhados em várias posições e ruas ou ainda, que estão alocados erroneamente (o controle sistêmico está registrado em um endereço e, o físico, em outro). Esse é um fator que se deve melhorar, visto que, geram divergências de estoque. É um processo que exige muita atenção.

3) Inventário cíclico e processo de exportação: o inventário cíclico é feito diariamente para controle e ajuste de estoque. No entanto, notou-se que, quando é realizado o processo de exportação (envio de materiais para outras filiais fora do Brasil) geram-se outras contagens, devido aos itens não constarem em seus endereços no ato do inventário, ou seja, o saldo permaneceu no endereço sendo que o material foi retirado. Em outras palavras, a baixa do material separado, não é feita de imediato durante o processo de exportação, fato esse que ocasiona divergências desnecessárias na contagem cíclica.

4) Utilização do método FEFO: outro ponto analisado foi a utilização do método de avaliação de estoque FEFO, o qual não é seguido da forma correta, no que se refere aos itens com prazo de validade, posto que há uma quantidade considerável de itens que vão vencer e não poderiam ser comercializados. Nesse sentido foi observado que, os itens com prazo maior estão saindo primeiro e os que expiram antes, estão ficando em estoque. Essa é operação que tende estar sendo feita, de forma equivocada, pois o material pode ser perdido gerando um custo para a empresa.

5) Separação dos materiais: esse processo é feito manualmente, o qual impacta diretamente no estoque da empresa, requerendo assim, muita atenção. É outro aspecto que é importante analisar, visto que, parte das divergências do estoque é devido à separação errada no material. Constata-se que essas discordâncias (entre o físico e o sistêmico) decorrem devido ao fato da execução do picking de determinado item ser feita com um lote e, o registro ser feito com outro no sistema. Isso significa que há sobra de um lote e falta de outro de um mesmo SKU.

6) Lançamentos de entrada e saída de materiais: os lançamentos de entrada e saída de itens é sem dúvidas, um fator que se faz necessário melhorar, pois é outro, o qual provoca 
divergências de estoque na empresa. Verificou-se que isso ocorre, geralmente, no atendimento e devolução de kits de cirurgia (descartáveis e instrumentais), já que a companhia possibilita um processo de consignação desses materiais, para os hospitais atenderem aos pacientes. Esse equívoco foi avaliado com a execução dos inventários cíclicos, haja vista foi percebido, o surgimento de SKU sem estoque, sem a existência de saldo sistêmico bem como inverso. Dessa forma há o registro de um produto, sendo que, na realidade, não há o físico, fato esse que ocasiona retrabalho.

7) Volume alto de material sem saldo sistêmico: no que se refere aos itens estocados sem constar sistemicamente no estoque, observou-se que o volume é consideravelmente grande. Isso é decorrente da má execução dos processos anteriormente descritos. Nesse sentido, a empresa afirma que:

Inconsistências nos processos Outbound acabam gerando esses tipos de problema à medida que as movimentações de saldo $\mathrm{x}$ físico não são feitas corretamente. Para exemplificar, a empresa trabalha com dois processos principais na divisão de negócios $\mathrm{ASD}$, que é a venda para distribuidores e atendimento de cirurgias. Para esses processos existem dois armazéns principais: o armazém geral, que abastece a venda indireta (distribuidor) e venda direta (cirurgia) e o armazém de cirurgia. Nesse segundo são feitas todas as movimentações de logística reversa para atendimento de cirurgias, desde montagens de kits e reposição dos mesmos, separação, expedição e recebimento do material retornado do hospital. $\mathrm{O}$ processo logístico final seria o apontamento do consumo feito pelo instrumentador na cirurgia. Se esse apontamento não for realizado de forma correta gera um saldo incorreto para consumo e o produto pode acabar ficando sem saldo em estoque.

Conforme mencionado anteriormente, há uma quantidade considerável de materiais imobilizados (físico) e que não estão registrados no ERP da empresa. Isso tende a ser um problema muito grave, uma vez que, se uma falha desse tipo persistir, a organização terá prejuízo de grande impacto em seu faturamento, além de apresentar altos custos com a importação de produtos que a mesma já possui.

8) Atenção na realização dos processos e trabalho em equipe: esse é o ponto chave dos equívocos operacionais até aqui descritos. Percebe-se que as falhas são constantes, porque não há a devida atenção do colaborador com a atividade que o mesmo está

Revista ENIAC Pesquisa, Guarulhos (SP), V.8, n.1, jan.- jun. 2019. 
executando. $\mathrm{O}$ trabalho em equipe também influência sensivelmente, pois, nota-se que nem todos manifestam o interesse em saber qual é o trabalho que seu colega está executando, ou seja, há individualismo por parte dos próprios colaboradores, fato esse que não é bom para o desempenho geral das atividades dentro do Centro de Distribuição.

9) Custos de estoque: além dos comentários anteriormente citados, outros fatores podem impactar o faturamento da empresa, tal como, os custos decorrentes de estoque. Esses custos estão relacionados às perdas ocasionadas no manuseio dos materiais, na realização dos processos e da pouca utilização do método de avaliação FEFO. Observa-se que, de acordo com o Setor de Finanças da empresa, esses custos, no ano de 2017 (decorrentes de produtos vencidos) foram em torno de RS 1.550.000,00.

Segundo as informações coletadas, a empresa faturou mais de 35 milhões de reais durante o ano de 2017, porém, conforme o gráfico 1, as perdas com materiais descartados correspondem a $4 \%$ desse valor.

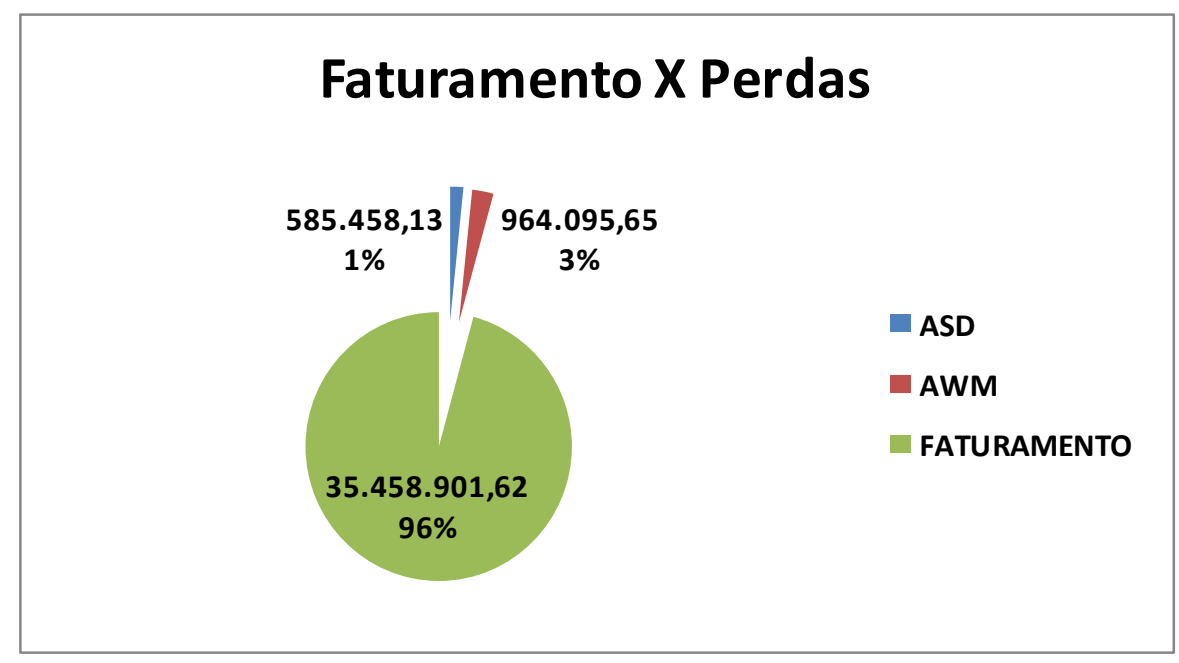

Gráfico 1: Análise das perdas (materiais descartados AWM) no faturamento

Fonte: Elaborado pelos autores

De acordo com o relato anterior, além do agravo com os materiais perdidos, a empresa ainda necessita arcar com o destino final dos mesmos, ou seja, com o processo de incineração.

Revista ENIAC Pesquisa, Guarulhos (SP), V.8, n.1, jan.- jun. 2019. 


\section{Sugestões de melhorias}

De acordo com os fatores anteriormente analisados, entende-se que a primeira ação a ser considerada é a realização de um planejamento de treinamento e requalificação dos funcionários, haja vista que, as falhas nos processos são decorrentes de erros humanos, seja por falta de atenção ou de informação. O processo de requalificação é necessário para eliminar os vícios no ato dos procedimentos que serão ou estão sendo executados. O treinamento é indicado, principalmente aos novos colaboradores, visando que iniciem suas atividades da maneira correta, conscientes da importância da realização de cada processo feito adequadamente. As sugestões anteriores (treinamento e requalificação) são uteis também para fazer com que os funcionários compreendam e pratiquem o senso de organização, pois quanto mais bem organizados e acondicionados forem os itens em suas alocações, melhor será a composição do estoque visualmente. Desordem é sinônimo de descuido.

Com relação ao equívoco no endereçamento dos itens é importante que os materiais sejam endereçados em uma única rua, se possível no mesmo prédio de alocações (porta-pallets ou prateleiras), dependendo da quantidade. Essa ação facilitará a localização, a contagem e a separação dos itens.

O inventário cíclico será mais bem aplicado, antes ou depois do processo de exportação, visto que a movimentação de material durante o inventário vai ocasionar outras contagens que poderiam não surgir com os processos sendo feitos separadamente. Isso garantirá a efetividade da contagem física, ou seja, vai registrar o que, de fato tem em estoque. Caso a empresa opte pelos dois processos ao mesmo tempo é imprescindível, que a baixa dos itens separados seja realizada simultaneamente no sistema ERP, ou seja, de imediato.

A utilização dos métodos FEFO e FIFO deve ser um procedimento obrigatório e constante no abastecimento e na separação dos materiais para pedidos de venda. Aquele material que apresentar validade mais próxima é o que deve ser separado, evitando assim, desperdícios e descartes de produtos vencidos.

A separação manual e lançamentos de entrada e saída de materiais exigem muita concentração e atenção, portanto, o foco do funcionário nessas atividades é essencial. Esse deve se certificar que separou ou recebeu o item e o lote certos e, lançar no sistema. Em hipótese alguma, o mesmo deve endereçar ou retirar material sem dar baixa no sistema 
informatizado (ERP). Em consequência disso, o volume de material, sem saldo sistêmico tenderá a diminuir, ou será eliminado.

É necessário também salientar a importância do trabalho do Departamento de Qualidade na redução de itens avariados, seja pelo manuseio ou alocação nos devidos endereços. É necessária maior fiscalização, por parte dos responsáveis, visando evitar a perda de material, por simples descuido.

Tão importante quanto as sugestões já apontadas anteriormente é a questão do trabalho em equipe. Essa é uma questão que deve ser aprimorada, pois os funcionários devem desenvolver suas atividades tendo o pleno conhecimento daquilo que estão executando, haja vista que, a execução de certa atividade, certamente irá impactar no trabalho de um outro funcionário, Além disso, o funcionário que estiver ocioso poderá auxiliar aquele que está muito atarefado, de modo que, esse possa contribuir para a finalização da atividade que o colega está executando. Por fim, a gerência do setor deve acompanhar os processos de perto e identificar quais estão falhos visando, de imediato apresentar ações que busquem minimizar os possíveis equívocos, bem como avaliar o desempenho dos funcionários.

\section{CONSIDERAÇÕES FINAIS}

Gerir e controlar estoques são atividades distintas, mas são totalmente integradas. Não há como executar um sem impactar em outro. Métodos de avaliação e técnicas de gestão e controle de estoque devem ser utilizados pelo gestor, para que o mesmo administre seu estoque e promova ações necessárias para otimizar os processos. Nesse contexto, a presente pesquisa possibilitou identificar e avaliar os principais impactos gerados com a utilização desses instrumentos, a fim de observar o que de fato estava gerando impactos efetivos, bem como o que poderia ser melhorado. A mesma permitiu também, analisar os processos relacionados à gestão e controle de estoques.

Por meio da pesquisa de campo foi ratificado que a não utilização adequada das técnicas e ferramentas de gestão e controle de estoque causam impactos negativos e custos desnecessários. A empresa investigada retrata, o quanto é importante o emprego dessas técnicas, justamente porque apresenta equívocos processuais e operacionais, os quais poderiam ser evitados, caso procedesse de maneira apropriada. $\mathrm{O}$ estudo apontou alguns pontos de melhoria, sendo os principais: atenção na separação dos materiais; endereçamento

Revista ENIAC Pesquisa, Guarulhos (SP), V.8, n.1, jan.- jun. 2019. 
correto e a utilização do método FEFO para controle de estoque. A análise dos dados também aponta que, a empresa deveria procurar diminuir suas perdas com os itens vencidos e/ou avariados, visto que, além dos custos gerados com o descarte desses materiais, a mesma incorre em custos devido a itens não conformes, custos esses que poderiam ter sido parte da receita ou do faturamento da empresa, conforme análise apresentada no gráfico 1.

É importante ressaltar que, a falta de monitoramento dos processos pela gestão da empresa, impacta diretamente no comportamento e no desempenho dos colaboradores, no que se refere a realização dos procedimentos operacionais, haja vista que, as análises aqui descritas tendem a evidenciar que, alguns equívocos relatados são decorrentes de falta de concentração e atenção por parte dos colaboradores. Isso tende a significar que, o monitoramento do desempenho dos colaboradores é um aspecto que necessita ser urgentemente revisto.

\section{REFERÊNCIAS}

ALMEIDA, H. J.; SARAIVA, J. F.; SOUZA, M. S. Uma avaliação do processo de gestão e controle de estoques realizado por uma empresa prestadora de serviços logísticos in house. Revista Fatec Zona Sul. São Paulo, v. 2, nº 1, 2015.

ALMEIDA, M. C. Auditoria: Um curso moderno e completo. $7^{\text {a }}$ ed. São Paulo: Atlas, 2010.

ANDRADE, L. Controle de Estoque. Revista Faculdade Montes Belos, v. 4, n. 2, nov. 2011.

BORGES, W. Implantação de ferramentas para controle de estoque: Estudo de caso em uma Fábrica de Ração. Tese (graduação) apresentada a Universidade de Rio Verde, Engenharia de Produção, Goiás, 2015.

COSTA, Maria L. M. Monteiro. Proposta de implantação de uma política de gestão de estoques no restaurante Pitaya (Natal/RN).Trabalho de conclusão de curso (bacharel) apresentado à Faculdade Federal do Rio Grande do Norte/UFRN, Natal, 2015.

DANTAS, J. C. A. A importância do controle de estoque: Estudo realizado em um supermercado na cidade de Caicó/RN. Monografia (bacharel) apresentado à Faculdade Federal do Rio Grande do Norte/UFRN, Caicó, 2015.

DENTZ, J. (2016). Como fazer controle de estoque passo a passo. Disponível em: https://blog.contaazul.com/como-fazer-controle-de-estoque-passo-a-passo. Acesso em 20/10/2017.

DORNIER, F. P. et al. Logística e Operações Globais. 1ª ed., São Paulo: Editora Atlas, 2007.

DUARTE, F (2015). Saiba o que é FIFO, LIFO, FEFO, PEPS e UEPS, sua relação e aplicação. Disponível em: https://pt.linkedin.com/pulse/saiba-o-que-\%C3\%A9-fifo-lifo-

Revista ENIAC Pesquisa, Guarulhos (SP), V.8, n.1, jan.- jun. 2019. 
fefo-peps-ueps-sua-rela $\% \mathrm{C} 3 \% \mathrm{~A} 7 \% \mathrm{C} 3 \% \mathrm{~A} 30-\mathrm{e}-\mathrm{aplica} \% \mathrm{C} 3 \% \mathrm{~A} 7 \% \mathrm{C} 3 \% \mathrm{~A} 3 \mathrm{o}$. Acesso em $15 / 09 / 2017$.

FERREIRA, S. S. S. O centro de distribuição da Drogaria Santa Marta: Um estudo de caso. Tese (mestrado) apresentada a Faculdade Faria Alves, Goiânia, 2016.

FRANCISCHINI, P. G.; GURGEL, F. A. Administração de Materiais e do Patrimônio. Edição única, São Paulo: Editora Thonson Pioneira, 2002.

FRAZÃO, Dilva. (2015). Vilfredo Pareto. Disponível em: https://www.ebiografia.com/vilfredo pareto/. Acesso em 29/09/2017.

GOMES, R. P.; MILAN. W. W. Gestão de estoque pelo método do estoque máximo-mínimo em uma empresa de médio porte do ramo de revenda de combustível em Carneirinho- MG. Revista Organizações e Sociedade, Iturama, v.6, n5, p. 19-36, jan/jun, 2017.

GONÇALVES, L. C. Gestão e controle de estoques. Notas de Aula. Faculdade de Tecnologia da Zona Sul/FATEC, São Paulo, 2017.

GONÇALVES, L. C. Técnicas e Indicadores para Controle de Estoque. Notas de Aula. Faculdade de Tecnologia da Zona Sul, São Paulo, 2017.

HUGO, G. B. et al. Inventory management: a case study in a smallenterpriseoftheelectronics sector. Revista Produção em Foco, Florianópolis, v.6, n2, p. 66-74, 2016.

IMPORTÂNCIA do controle de estoque de mercadorias para as empresas comerciais. Disponível em: http://www.administradores.com.br/artigos/tecnologia/importancia-docontrole-de-estoque-de-mercadorias-para-as-empresas-comerciais/13788/. Acesso em: 20/10/2017.

JACOBSEN, M. Logística Empresarial: Ciências sociais aplicadas. $3^{\text {a }}$ ed. Itajaí: Universidade do Vale do Itajaí, 2009.

KARPSTEIN, A. A. (2017). Artroscopia: O que você precisa saber sobre essa nova técnica minimamente invasiva. Disponível em: http://www.ortopediabr.com.br/artroscopia. Acesso em 09/09/2017.

KOXNE, D.et al. Controle e Custos de estoque em empresa comercial: um estudo de caso de empresa comercial varejista importadora. Tese apresentada no XIII Congresso Brasileiro de Custos, Belo Horizonte, 2006.

MACIEL, L. F. V. B. et al. Análise da acuracidade na gestão de estoque em uma empresa do ramo metal mecânico de Chapecó/SC. In: ANAIS DE ENGENHARIA DE PRODUÇÃO, 2013, Chapecó. Anais. Chapecó: UCEFF, v.1, n.1, p.20-36, ago, 2017.

MARTELLI, L. L.; DANDARO, F. Planejamento e Controle de Estoque nas Organizações. Revista Gestão Industrial. Paraná, v.11, n.02, p. 170-185, 2015.

MARTINS, Eliseu. Contabilidade de Custos. 9a ed. São Paulo, Editora Atlas S.A, 2003.

Revista ENIAC Pesquisa, Guarulhos (SP), V.8, n.1, jan.- jun. 2019. 
MARTINS, P.; CAMPOS ALT, P. R. Administração de Materiais e Recursos Patrimoniais. $3^{\text {a }}$ ed. São Paulo: Editora Saraiva, 2009.

MONDARDO JUNIOR, J. Gestão de Estoque: Análise da curva ABC em uma empresa de materiais de construção localizada no município de Timbé do Sul - SC. Trabalho de conclusão de curso (bacharel) apresentado à Faculdade do Extremo Sul Catarinense/UNESC, Criciúma, 2016.

MONFRON, C. M. B. et al. Gestão de estoque para a acuracidade das informações. Revista de Contabilidade, Ciência da Gestão e Finanças, Caxias do Sul, v.1, n. 1, p.40-53, 2013.

PESSOA, T. R; KRAUSE, J. Cálculo e Controle dos custos de produção: Como controlar as matérias primas e administrar os gastos. Revista Organização Sistêmica, v.5, n.3, jan/jun 2014.

PETROLI, G. F.; JÚNIOR, I. P. A classificação ABC no planejamento e controle de estoque: Estudo de caso em empresas da região de Lins (SP).Trabalho de conclusão de curso (tecnólogo) apresentado à Faculdade de Tecnologia de Lins/FATEC, Lins, 2012.

PONTES, A. E. L. Gestão de Estoques: Utilização das ferramentas curva ABC e classificação XYZ em uma farmácia hospitalar. Trabalho de conclusão de curso (bacharel) apresentado à Faculdade Federal da Paraíba/UFPB, João Pessoa, 2013.

POZO, H. Administração de Recursos Materiais e Patrimoniais-Uma Abordagem Logística. $4^{\mathrm{a}}$ ed. São Paulo, Editora Atlas, 2007.

RIBEIRO, F. et al. Gestão de estoque de óleo diesel marítimo: Impacto no controle físico. Revista UNIABEU, Nova Iguaçu, v.10, n25, p. 170-185, maio/ago, 2017.

RODRIGUES, R. F.; GUIMARÃES, J. C. F.; SEVERO, E. A. Acuracidade de estoque. In: SIMPÓSIO CIENTÍFICO FTSG DE GRADUAÇÃO E PÓS-GRADUAÇÃO, 3.; 2013, Bento Gonçalves. Anais. Bento Gonçalves: FTSG, p.01-21, 2013.

ROSA, M. (2016). 10 dicas para um controle de estoque eficiente. Disponível em: http://brasaosistemas.com.br/blog/6-dicas-para-um-controle-de-estoque-eficiente/. Acesso em $24 / 10 / 2017$.

SERAFIM, J. C. Gestão de Estoque: um estudo em uma indústria metalúrgica do extremo sul de Santa Catarina. Trabalho de conclusão de curso (bacharel) apresentado à Faculdade do Extremo Sul Catarinense/UNESC, Criciúma, 2016.

SILVA, F. M.; CARDOSO, V. C. Análise dos controles internos de estoque de produtos prontos: estudo de caso em uma distribuidora de aço da cidade de Cachoeirinha - RS. RAC Revista de Administração e Contabilidade, Santo Ângelo, v.15, n. 30, p. 03-25, jul/dez, 2016.

SILVA, R. B. A avaliação e controle dos estoques e suas influencias no resultado de empresas. Monografia (bacharel) apresentada a Universidade Federal de Santa Catarina, 2003 .

Revista ENIAC Pesquisa, Guarulhos (SP), V.8, n.1, jan.- jun. 2019. 
VICENZI, B.; SILVA, I. A. Processos e controles internos de estoque em uma empresa de produção customizada. In: IX SEMINÁRIO DE INICIAÇÃO CIENTÍFICA CURSO DE CIÊNCIAS CONTÁBEIS, 2014, Caxias do Sul. Anais...Caxias do Sul: FSG, v.5, n.2, 2014.

VIEIRA, N. P. Análise dos fatores que afetam a gestão de estoques da família de esmaltes em uma indústria cerâmica no extremo sul catarinense. Trabalho de conclusão de curso (bacharel) apresentado à Faculdade do Extremo Sul Catarinense/UNESC, Criciúma, 2016.

Revista ENIAC Pesquisa, Guarulhos (SP), V.8, n.1, jan.- jun. 2019. 